\title{
Pressure-Volume-Temperature Relations in Liquid and Solid Tritium
}

Volume 98

\section{E. R. Grilly}

Los Alamos National Laboratory, Los Alamos, NM 87545

\begin{abstract}
$P V T$ relations in liquid and solid $\mathrm{T}_{2}$ near the melting curve were measured over $20.5 \mathrm{~K}-22.1 \mathrm{~K}$ and $0 \mathrm{MPa}-7 \mathrm{MPa}$ (0 bar-70 bar) with a cell that used diaphragms for pressure and volume variation and measuremcnt. Because of ortho-para self conversion, the melting pressure $P_{\mathrm{m}}$ and the liquid molar volume $V_{\mathrm{Im}}$ increased with time. The rates wcre consistent with a second order rcaction similar to that for $c$ the $J=$ odd concentration:$$
\mathrm{d} c / \mathrm{d} t=-k_{1} c^{2}+k_{2} c(1-c),
$$

where $k_{1}=6-9 \times 10^{-2} h^{-1}$. By extrapolation, the ortho and para forms dif-
\end{abstract}

fered by $\Delta P_{\mathrm{m}} \sim 6$ bar and $\Delta V_{\mathrm{Im}} \sim 0.5 \%$. Measurements of the volume change on melting and the thermal expansion and compressibility for liquid $\mathrm{T}_{2}$ were consistent with those for $\mathrm{H}_{2}$ and $\mathrm{D}_{2}$. Impurities such as $\mathrm{H}_{2}, \mathrm{HT}$, DT, and ${ }^{3} \mathrm{He}$ were removed by a technique using an adsorption column of cold activated alumina. Corrections for ${ }^{3} \mathrm{He}$ growth during an cxpcriment were adequate except near the triple point.

Key words: deuterium; hydrogen; $P V T$ relations; tritium.

Accepted: September 24, 1993

\section{Introduction}

Basic interest in the hydrogens $H_{2}, D_{2}$, and $T_{2}$ is notably enhanced by the existence of significant zero-point energy, large relative mass differences, and different ortho-para characteristics. In addition, $\mathrm{D}_{2}$ and $\mathrm{T}_{2}$ in the condensed phases are prime candidates as fuels for controlled nuclear fusion.

Although the discoveries of $D_{2}$ in 1931 [1] and $T_{2}$ in 1934 [2] were close together in time, the pressure-volume-temperature $(P V T)$ measurements on $T_{2}$ have lagged far behind those on $D_{2}$. Essentially they were the 1951 measurements of vapor pressure [3] and liquid density [4] up to 3 bar $^{1}$ and 29

\footnotetext{
${ }^{1}$ The bar $\left(=10^{5} \mathrm{~Pa}\right)$ is used in this paper rather than the pascal in order to facilitate the comparison of the results of this work with the results of previous and similar work. It should bc noted that the International Committee for Weights and Measures allows the use of the bar temporarily with the International System of Units.
}

$\mathrm{K}$ and the 1956 melting curve determination up to 3100 bar and $60 \mathrm{~K} \mathrm{[5].} \mathrm{Contributing} \mathrm{to} \mathrm{the} \mathrm{sluggish-}$ ness of research efforts have been the high cost of $\mathrm{T}_{2}$ and the difficulties that arise from its radioactivity $\left(2.8 \mathrm{Ci} / \mathrm{cm}^{3} \mathrm{STP}\right.$ gas). Health and environment concerns require great care in containing $T_{2}$ and definite provisions for accidental release. The continual creation of ${ }^{3} \mathrm{He}$ from nuclear decay automatically adds a significant impurity. Self-heating demands proper equipment design and/or data corrections. The exchange of tritium with hydrogen in equipment causes physical breakdown of plastics and contamination of the tritium with hydrogen. These problems have affected the accuracy and completeness of the data reported here. 


\section{Apparatus and Procedures}

The apparatus and procedures were basically those used for similar studies on ${ }^{3} \mathrm{He}[6],{ }^{4} \mathrm{He}$ [7], $\mathrm{D}_{2}$ [8], and $\mathrm{H}_{2}$ [9]. The experimental cell consisted of three $\mathrm{BeCu}$ diaphragms welded at their circumferences and separated by $0.3 \mathrm{~mm}$ gaps. The lower gap, connected to a room-temperature He gas handling system via a capillary tube, had its pressure adjusted and measured directly. The upper gap was the $\mathrm{T}_{2}$ experimental chamber and was connected to the room-temperature $T_{2}$ handling system via a low-temperature valve and a capillary tube. The sample pressure was determined from the deflection of the upper diaphragm, measured by electric capacitance. The experimental volume was determined from the pressures in the two gaps, using the calibrations described in Ref. [8].

The $T_{2}$ system is shown schematically in Fig. 1. Four stainless steel tanks, each of $1500 \mathrm{~cm}^{3}$ volume, were used to hold $T_{2}$, either for storage or for transfer to various parts of the system. The $T_{2}$ was pumped at low pressure with a rotary vane pump and compressed to 70 bar with a diaphragm compressor. The uranium bed (U), Pd diffuser (Pd), and $\mathrm{Al}_{2} \mathrm{O}_{3}$ adsorption tube $\left(\mathrm{Al}_{2} \mathrm{O}_{3}\right)$ were used for $T_{2}$ purification. $T_{2}$ gas samples were collected in sample tubes and analyzed by mass spectrometer. Calibration of capacitance versus cell pressure was done with the cell valve (V20) open and the $T_{2}$ separated from the oil piston gauge by a differential pressure indicator (DPI). To prevent excessive pressure in the cell upon loss of cooling when V20 was closed, a thermocouple on the cell signaled a motor to open V20, which allowed venting to a tank via a pressure relief valve (PRV). The plastic material in the cell valve tip and in the stem seals of the manipulative valves was the polyimide Vespel SP 211, which resisted the destructive action of $T_{2}$ quite well.

\section{Purification}

A significant problem in $T_{2}$ experiments is the growth of ${ }^{3} \mathrm{He}$ from radioactive decay at the rate of $0.031 \%$ per day. It was anticipated that a ${ }^{3} \mathrm{He}-\mathrm{T}_{2}$ mixture would behave like a ${ }^{4} \mathrm{He}-\mathrm{H}_{2}$ mixture in solubility and effect on PVT measurements. The ${ }^{3} \mathrm{He}$ growth during an experiment (at most $76 \mathrm{~h}$ long) was not expected to exceed solubility limits. Thus it was felt that the PVT measurements could be adequately corrected for ${ }^{3} \mathrm{He}$ growth during an experiment but it was mandatory that the experiment start with ${ }^{3} \mathrm{He}$-free $\mathrm{T}_{2}$. Several methods of removing ${ }^{3} \mathrm{He}$ were used. Exposure to $\mathrm{U}$ at $300 \mathrm{~K}$ binds $\mathrm{T}_{2}$ as $\mathrm{UT}_{3}$ and allows the unabsorbed ${ }^{3} \mathrm{He}$ to be pumped away but good removal requires several cycles. A Pd tube diffuser retains all gases except the hydrogens. But these methods are slow and do not remove hydrogen and deuterium, which are initially present or appear in the gas when most materials are exposed to $T_{2}$. Therefore the final process used was desorption from $\mathrm{Al}_{2} \mathrm{O}_{3}$, following basically the method of Depatie and Mills [10] for preparation of $99 \%$ o- $\mathrm{H}_{2}$ or $\mathrm{p}-\mathrm{D}_{2}$. About $32 \mathrm{~cm}^{3}$ of $2 \mathrm{~mm}$ dia. pellets of $\mathrm{Al}_{2} \mathrm{O}_{3}$ was placed in a $21 \mathrm{~cm}$ long stainless steel tube $(15.3 \mathrm{~mm}$ O.D. and $0.28 \mathrm{~mm}$ wall). At the center of this was a stainless steel tube (3.2 mm O.D. and $0.25 \mathrm{~mm}$ wall) for with-

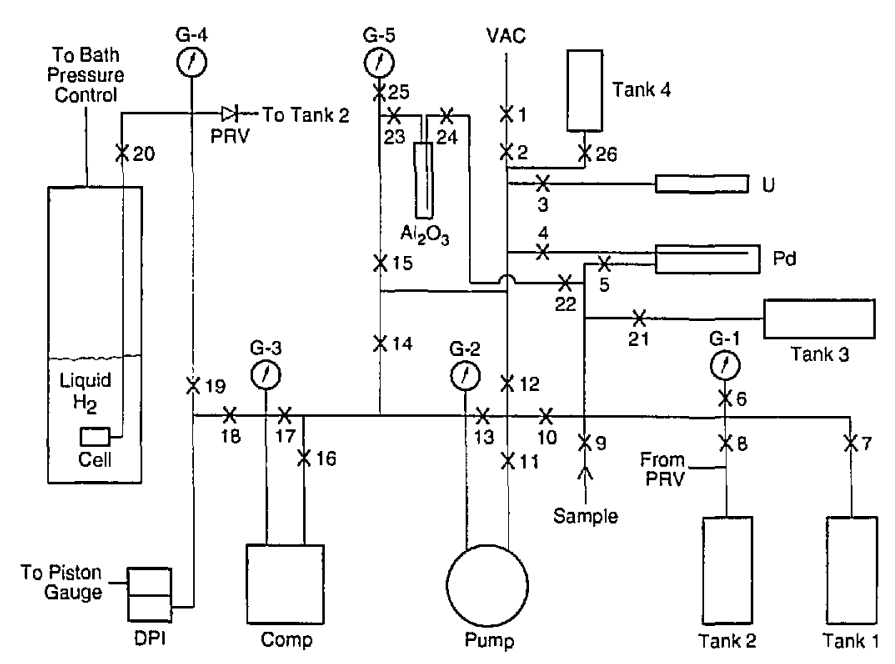

Fig. 1. Schematic of tritium $P V T$ system. 
drawing the gas. Prior to use, the $\mathrm{Al}_{2} \mathrm{O}_{3}$ was evacuated at $140^{\circ} \mathrm{C}$ for $2 \mathrm{~h}$. The impure gas was added to the $\mathrm{Al}_{2} \mathrm{O}_{3}$ tube immersed in liquid $\mathrm{H}_{2}$ until saturation occurred at 87 mbar, after which it was passed through the tube at 87 mbar. The gas entered the top of the $\mathrm{Al}_{2} \mathrm{O}_{3}$ column and exited from the bottom until the exiting gas composition was the same as that of the entering gas, at which time flow was stopped. Then the liquid $\mathrm{H}_{2}$ bath was lowered slowly until the effluent gas was almost pure $\mathrm{T}_{2}$, after which the gas was collected separately while the adsorption tube warmed to room temperature. A pre- $\mathrm{T}_{2}$ test on $\mathrm{D}_{2}$ containing $0.61 \% \mathrm{HD}$ produced $3500 \mathrm{~cm}^{3} \mathrm{STP} \mathrm{D}_{2}$ with $0.03 \% \mathrm{HD}$. For $\mathrm{T}_{2}$ initially containing $0.26 \% \mathrm{H}_{2}, 1.97 \%{ }^{3} \mathrm{He}, 7.34 \%$ $\mathrm{HT}$, and $0.49 \% \mathrm{DT}$, Table 1 gives the composition of effluent gas samples taken at various points of withdrawal. Collection of the gas after $V=1600$ $\mathrm{cm}^{3}$ yielded $1600 \mathrm{~cm}^{3} \mathrm{~T}_{2}$ containing $0.18 \% \mathrm{H}$, $0.10 \% \mathrm{D}$, and $<0.01 \%{ }^{3} \mathrm{He}$ which was enough for a $P V T$ run.

Table 1. Gas composition (\%) as a function of effluent volume

\begin{tabular}{lrrrrr}
\hline$V\left(\mathrm{~cm}^{3} \mathrm{STP}\right)$ & 600 & 900 & 1200 & 1600 & 3200 \\
\hline $\mathrm{H}_{2}$ & 3.71 & 0.080 & 0.064 & 0.046 & 0.028 \\
${ }^{3} \mathrm{He}$ & 0.90 & 0.010 & $<0.01$ & $<0.01$ & $<0.01$ \\
$\mathrm{HT}$ & 75.84 & 5.66 & 0.36 & 0.38 & 0.20 \\
$\mathrm{DT}$ & 2.50 & 0.54 & 0.46 & 0.36 & 0.06 \\
$\mathrm{~T}_{2}$ & 17.05 & 93.62 & 99.12 & 99.21 & 99.72 \\
\hline
\end{tabular}

\section{Ortho-Para Considerations}

The equilibrium ortho-para composition in $\mathrm{T}_{2}$ for various temperatures was calculated by Jones [11] and Gaines, Tsugawa, and Souers [12] and measured by Frauenfelder, Heinrich, and Olin [13]. The Gaines et al. results $(T \leqslant 22.5 \mathrm{~K})$ agreed fairly well with the Jones results, which covered $0 \mathrm{~K}-175 \mathrm{~K}$. The measurements [13] gave somewhat higher values of $c$, the $J=$ odd concentration, which could result from a higher sample temperature than the thermometer reading because of the radioactive heating. The Jones calculation is used as the standard in this paper.

The equilibrium values $c$ (e) versus temperature $T$ for $\mathrm{H}_{2}, \mathrm{D}_{2}$, and $\mathrm{T}_{2}$ are shown to $100 \mathrm{~K}$ in Fig. 2 . The normal (n) values (those at $T=300 \mathrm{~K}$ ) are 0.75 for $\mathrm{H}_{2}$ and $\mathrm{T}_{2}$ and 0.33 for $\mathrm{D}_{2}$. While $c(\mathrm{e})$ for $\mathrm{H}_{2}$ and $\mathrm{D}_{2}$ at $20 \mathrm{~K}$ is very small and insensitive to $T$, $c(\mathrm{e})=0.34$ for $\mathrm{T}_{2}$ and increases rapidly with increasing $T$. Furthermore, the o-p conversion in $T_{2}$ is

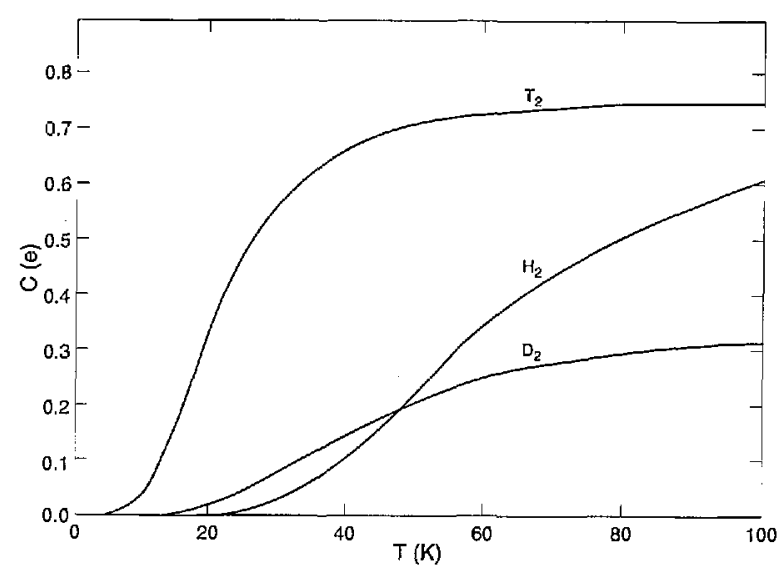

Fig. 2. Concentration of $J=$ odd states in the hydrogens at equilibrium vs temperature.

much faster than in $\mathrm{H}_{2}$ under similar conditions. Therefore, it is important to determine $c$ during the PVT measurements on $\mathrm{T}_{2}$. The variations of $c$ with time $t$ and vapor pressure were measured and partially reported earlier [14]. There, the values of $c$ were derived from gas thermal conductivity measurements on samples from the condensed phase, thus the rapid back conversion, $p \rightarrow 0$, in the gas phase decreased reliability somewhat. The best fits of the data were: for the solid,

$$
\mathrm{d} c / \mathrm{d} t=-k c^{2}
$$

and for the liquid,

$$
\mathrm{d} c / \mathrm{d} t=-k_{1} c^{2}+k_{2} c(1-c)
$$

where $k$ and $k_{1}$ are empirical rate constants and $k_{2}=k_{1} c(\mathrm{e}) /(1-c(\mathrm{e}))$.

The results on o-p conversion are summarized in Table 2 in several useful forms: (a) $r_{0}$, the conversion rate at zero time; (b) $t_{1 / 2}$, the time to convert $1 / 2$ way to equilibrium; and (c) $k, k_{1}$, and $k_{2}$, the rate constants. In solid $T_{2}$, the observed $t_{1 / 2}$ values of 2.0 $\mathrm{h}, 2.6 \mathrm{~h}$, and $8.1 \mathrm{~h}$ at $4.0 \mathrm{~K}, 15.0 \mathrm{~K}$, and $19.5 \mathrm{~K}$, respectively, are moderately consistent with the NMR results of Gaines et al. [12] and Sater et al. [15] (although the latter found a minimum at $11.4 \mathrm{~K}$ ) and with $1.5 \mathrm{~h}$ at $4 \mathrm{~K}$ of Frauenfelder et al. [13] using gas thermal conductivity analysis. However, Albers, Harteck, and Reeves [16] measured $0.28 \mathrm{~h}$ at $4 \mathrm{~K}$ with gas thermal conductivity. Our observed $t_{1 / 2}=8.3 \mathrm{~h}$ in liquid at $20.7 \mathrm{~K}$ also agrees with the Gaines et al. result. Thus, the conversion rates are about the same in liquid and solid near the triple point $(20.6 \mathrm{~K})$, which simplifies interpreting the 
Table 2. Ortho $\rightarrow$ para conversion in $\mathrm{T}_{2}$ at vapor pressure

\begin{tabular}{|c|c|c|c|}
\hline \multicolumn{4}{|c|}{ Solid } \\
\hline $\begin{array}{l}T(\mathrm{~K}) \\
c(\mathrm{e}) \\
k\left(\mathrm{~h}^{-1}\right) \\
r_{0}\left(\% \mathrm{~h}^{-1}\right) \\
t_{1 / 2}(\mathrm{~h})\end{array}$ & $\begin{array}{l}4.0 \\
0 \\
0.675 \\
38 \\
2.0\end{array}$ & $\begin{array}{l}15.0 \\
0.166 \\
0.321 \\
18 \\
2.6\end{array}$ & $\begin{array}{l}19.5 \\
0.325 \\
0.065 \\
4 \\
8.1\end{array}$ \\
\hline \multicolumn{4}{|c|}{ Liquid } \\
\hline $\begin{array}{l}T(\mathrm{~K}) \\
c(\mathrm{e}) \\
k_{1}\left(10^{-2} \mathrm{~h}^{-1}\right) \\
k_{2}\left(10^{-2} \mathrm{~h}^{-1}\right) \\
r_{0}\left(\% \mathrm{~h}^{-1}\right) \\
t_{1 / 2}(\mathrm{~h})\end{array}$ & & & $\begin{array}{l}24.4 \\
0.460 \\
6.32 \\
5.40 \\
2.5 \\
8.8\end{array}$ \\
\hline
\end{tabular}

PVT measurements on a liquid/solid mixture. The value of $k_{1} \sim 8 \times 10^{-2} \mathrm{~h}^{-1}$ is eight times the $k_{1}$ for $\mathrm{H}_{2}$ given by Woolley, Scott, and Brickwedde [17].

Vapor pressures of $\mathrm{T}_{2}$ at a certain $c$ value, $P(c)$, and of $n-T_{2} P(n)$, were measured simultaneously in a special two-cell system. The differences, $\Delta P=P(c)-P(\mathrm{n})$, are summarized in Table 3 . Their behavior follows that of $\mathrm{H}_{2}$ at similar values of $P(\mathrm{n})$, as in Woolley et al. [17]. For example, extrapolation of the $P(\mathrm{n})=840$ mbar data to $c=0$ gives $\Delta P=29 \mathrm{mbar}$ for $\mathrm{T}_{2}$ and $\Delta P=31 \mathrm{mbar}$ for $\mathrm{H}_{2}$.

Table 3. Vapor pressure of $T_{2}$ at various ortho values

\begin{tabular}{lccccc}
\hline \hline Phase & $\begin{array}{c}P(\mathrm{n}) \\
\mathrm{mbar}\end{array}$ & $\begin{array}{c}T \\
\mathrm{~K}\end{array}$ & \multicolumn{1}{c}{$\begin{array}{c}\Delta P \\
\text { mbar }\end{array}$} & $\begin{array}{c}\Delta P / \Delta c \\
\mathrm{mbar}\end{array}$ \\
\hline liquid & 840 & 24.4 & 0.66 & 6.0 & 67 \\
liquid & 840 & 24.4 & 0.54 & 12 & 57 \\
liquid & 840 & 24.4 & 0 & $(29)$ & $(39)$ \\
liquid & 228 & 20.7 & 0.48 & 4 & 15 \\
solid & 123 & 10.5 & 0.33 & 5.9 & 14 \\
solid & 116 & 19.4 & 0.46 & 4 & 14 \\
\hline
\end{tabular}

In the $P V T$ measurements above vapor pressure, gas thermal conductivity could not be used to determine $c$. Instead, the variations of melting pressure and liquid molar volume with time were used to determine o-p conversion rates. In these measurements, it was assumed that the initial value of $c$ was 0.75 because: (1) the purification process left the $\mathrm{T}_{2}$ sample at $c \sim 0.75$; and (2) the typical $2 \mathrm{~h}-5$ $\mathrm{h}$ storage times at $300 \mathrm{~K}$ and $1.1 \mathrm{bar}$ in a $1500 \mathrm{~cm}^{3}$ SS tank before condensation promoted conversion to $n-T_{2}$.

\section{Results}

The $P V T$ measurements typically began $2 \mathrm{~h}-3 \mathrm{~h}$ after condensation and continued for $50 \mathrm{~h}-76 \mathrm{~h}$. Usually a single loading of the cell at a given $T$ was used to measure compressibility and thermal expansion of liquid and solid, melting pressure, and volume change on melting. The liquid was compressed by a diaphragm until freezing began, which required 2 bar- 4 bar overpressure. After the cell pressure stabilized, the compression was slowly continued past completion of freezing, which was indicated by a rapid rise in pressure.

\subsection{Melting Pressures}

The melting pressures $P_{\mathrm{m}}$ discussed here were the first-freeze values, obtained by extrapolation to zero amount of solid. If the compression was delayed, the increase in $P_{\mathrm{m}}$ with time was attributed to o-p conversion and ${ }^{3} \mathrm{He}$ growth. The o-p change seemed to follow Eq. (2) where $c=0.75-\Delta P_{\mathrm{m}} / q$, $\Delta P_{\mathrm{m}}=P_{\mathrm{m}}(c)-P_{\mathrm{m}}(c=0.75), q=\Delta P_{\mathrm{m}} /(0.75-c)$, and $k_{1}$ and $q$ are constant at constant $T$. Measurements of $P_{\mathrm{m}}$ for ${ }^{4} \mathrm{He}-\mathrm{H}_{2}$ mixtures made up in the gas phase showed the regular effects of a slightly soluble gas and agreed fairly well with results of Bereznyak and Sheinina [18]. The mixture $P_{\mathrm{m}}$ increased 3 bar4 bar per $1 \%$ of ${ }^{4} \mathrm{He}$ over the $P_{\mathrm{m}}$ range of 0 bar -70 bar. Since ${ }^{3} \mathrm{He}$ formation in $\mathrm{T}_{2}$ is $1.29 \times 10^{-3} \%$ per hour, it was expected that ${ }^{3} \mathrm{He}$ dissolved in condensed $\mathrm{T}_{2}$ would increase $P_{\mathrm{m}}$ by $3.7 \mathrm{mbar}-5.0 \mathrm{mbar}$ $\mathrm{h}^{-1}$, which would necessitate small corrections. If saturation were exceeded, the ${ }^{3} \mathrm{He}$ would probably act as an ideal gas, i.e., $V$ varies as $P^{-1}$. Thus, the correction would be $60 \mathrm{mbar} \mathrm{h}^{-1}$ at the. lowest $P_{\mathrm{m}}$ $\left(2.4\right.$ bar at $20.55 \mathrm{~K}$ ), and $3.4 \mathrm{mbar}^{-1}$ at the highest $P_{\mathrm{m}}(70 \mathrm{bar})$. The ${ }^{3} \mathrm{He}$ growth in $76 \mathrm{~h}$ (the longest time after purification) is $0.098 \%$ whereas the ${ }^{4} \mathrm{He}-\mathrm{H}_{2}$ measurements in this cell and in Ref. [18] gave $0.16 \%{ }^{4} \mathrm{He}$ as the solubility limit at $2.4 \mathrm{bar}$ and $14 \mathrm{~K}$. It follows that ${ }^{3} \mathrm{He}$ would be expected to stay in solution. However, it apparently had left solution at $20.55 \mathrm{~K}$ when $P_{\mathrm{m}}$ and liquid compressibility $\beta_{1}$ were measured. Here the measured " $P_{\mathrm{m}}$ " was $2.4 \mathrm{bar}$, whereas linear extrapolation from higher $T$ gave $P_{\mathrm{m}}=0$. If the excess pressure all came from ideal gas ${ }^{3} \mathrm{He}$ the solubility would be $0.046 \%{ }^{3} \mathrm{He}$. Sherman (R. H. Sherman, personal communication) measured $0.077 \%$, which would result in $0.098-0.077=0.021 \%{ }^{3} \mathrm{He}$ as gas at $0.97 \mathrm{bar}$, which would yield 1.4 bar as the real $P_{\mathrm{m}}$. For this sample, the measured $\beta_{1}$ was 10 times "normal," i.e., values 
for $T_{2}$ aged $2 h-4 h$. Furthermore, $T_{2}$ with $52 h-70$ $\mathrm{h}{ }^{3} \mathrm{He}$ growth at $20.60 \mathrm{~K}$ and $20.65 \mathrm{~K}$ showed $\beta_{1}$ to be 4-7 times "normal." These high $\beta_{1}$ values must have been the result of gas in the cell. The ${ }^{4} \mathrm{He}-\mathrm{H}_{2}$ mixtures containing up to $1 \%{ }^{4} \mathrm{He}$, but below saturation, never gave $\beta_{1}$ values greater than $10 \%$ above pure $\mathrm{H}_{2}$ values. This throws suspicion on the high $P_{\mathrm{m}}$ and $\beta_{1}$ results for $\mathrm{T}_{2}$.

Taylor [19] summarized some experiments on condensed $\mathrm{T}_{2}$ in which ${ }^{3} \mathrm{He}$ had grown beyond the normal solubility limit. In liquid and solid $\mathrm{T}_{2}$ there was a lack of vapor pressure buildup consistent with the ${ }^{3} \mathrm{He}$ production rate. In another case, analysis of successive aliquots of gas removed from aged liquid $\mathrm{T}_{2}$ showed the last liquid was ${ }^{3} \mathrm{He}$-rich. Supplementary evidence for ${ }^{3} \mathrm{He}$ not appearing as gas was provided by electrical conductivity and magnetic susceptibility measurements. The formation of free ${ }^{3} \mathrm{He}$ was visually observed by Hoffer (J. K. Hoffer, personal communication), who condensed DT near the triple point in a cylindrical cell with sapphire windows at the ends [20]. After $8 \mathrm{~d}$ as a liquid, the DT showed no bubbles. (They could not be hidden in the fill tube, for it entered the bottom of the cell.) After a freeze and a melt, the sample showed a bubble at the top of the cell with a volume that was $\sim 1 \%$ of the ideal gas volume for $8 \mathrm{~d}{ }^{3} \mathrm{He}$ growth. A second freeze and melt produced the same bubble, which persisted for $3 \mathrm{~d}$. Then, within $12 \mathrm{~h}$ the bubble grew to $100 \%$ of the calculated volume for $12 \mathrm{~d}{ }^{3} \mathrm{He}$ growth, taking up $20 \%$ of the cell volume. During the next three days no change in the bubble was seen, even after a freeze and a melt. The behavior of ${ }^{3} \mathrm{He}$ grown in condensed $T_{2}$ seems to be unpredictable.

For this paper, the $P_{\mathrm{m}}$ measurements were corrected as if the ${ }^{3} \mathrm{He}-\mathrm{T}_{2}$ sample formed a solution like ${ }^{4} \mathrm{He}-\mathrm{H}_{2}$. Figure 3 shows $\Delta P_{\mathrm{m}}=P_{\mathrm{m}}(t)-P_{\mathrm{m}}(0)$ at $20.650 \mathrm{~K}, 21.900 \mathrm{~K}$, and $22.100 \mathrm{~K}$ with and without ${ }^{3} \mathrm{He}$ corrections. If the high rate at $20.65 \mathrm{~K}$ was caused by ${ }^{3} \mathrm{He}$ growth, it seems that a greater correction is needed. In the fit to Eq. (2), $q$ and the initial $\Delta P_{\mathrm{m}}$ were varied to get the most consistent $k_{1}$ for each run. The results, summarized in Table 4, show the similarities with the time variation of $c$ in liquid at vapor pressure (Table 2). The average value $q=6.0$ agrees with the $\mathrm{H}_{2}$ values 5.7-6.4 over $14 \mathrm{~K}-16 \mathrm{~K}$ from: $P_{\mathrm{m}}(\mathrm{p})$ by Youngblood [21]; $P_{\mathrm{m}}(\mathrm{n})$ by Mills and Grilly [5]; and $P_{\mathrm{m}}(\mathrm{p})$ and $P_{\mathrm{m}}(\mathrm{n})$ in the present apparatus.

Regardless of the previous discussion, extrapolation of $P_{\mathrm{m}}(t<6 \mathrm{~h})$ to $t=0$ gave $P_{\mathrm{m}}(\mathrm{n})$. For e- $\mathrm{T}_{2}$, values of $P_{\mathrm{m}}(\mathrm{e})$ with ${ }^{3} \mathrm{He}$ corrections were obtained from $q$ values or $P_{\mathrm{m}}(t \sim 50 \mathrm{~h})$. Corrections for

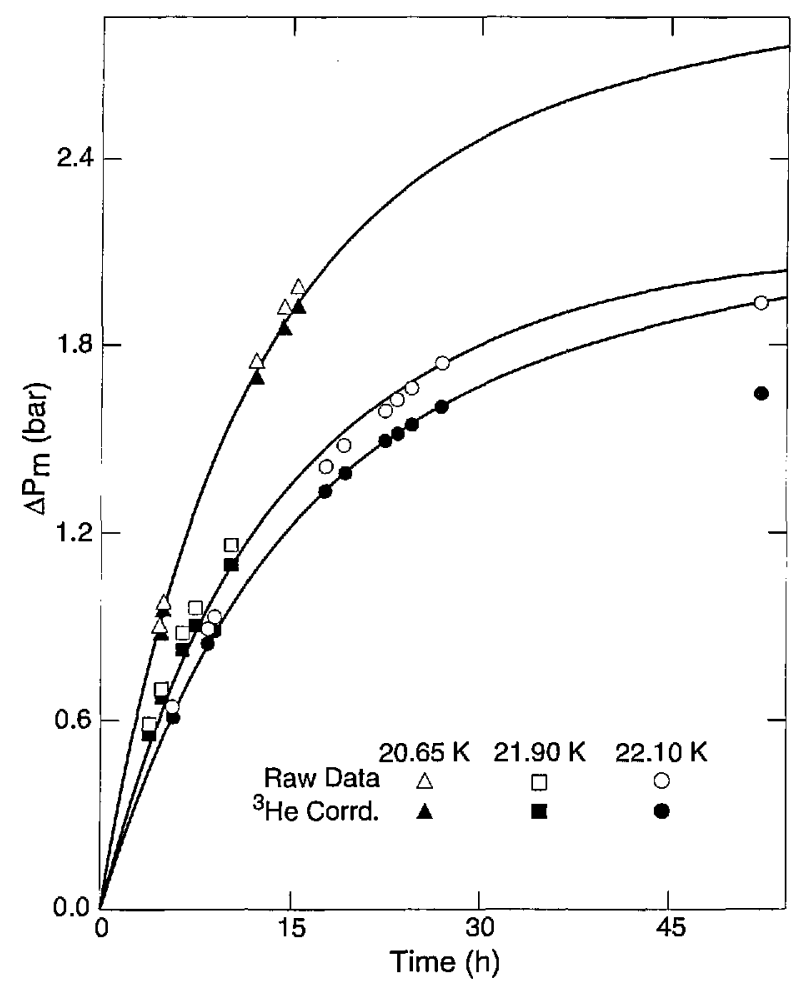

Fig. 3. Tritium melting pressure vs time at several temperatures.

Table 4. Ortho $\rightarrow$ para conversion in $\mathrm{T}_{2}$ from melting pressure change. Results in parentheses are from data uncorrected for ${ }^{3} \mathrm{He}$

\begin{tabular}{llcc}
\hline \hline$T(\mathrm{~K})$ & 20.65 & 21.90 & 22.10 \\
$P_{\text {mo }}(\mathrm{bar})$ & 3.295 & 58.630 & 67.906 \\
$c(\mathrm{e})$ & 0.358 & 0.393 & 0.400 \\
$k_{1}\left(10^{-2} \mathrm{~h}^{-1}\right)$ & $7.90(8.00)$ & $6.58(7.00)$ & $5.46(5.58)$ \\
$k_{2}\left(10^{-2} \mathrm{~h}^{-1}\right)$ & $4.41(4.46)$ & $4.26(4.53)$ & $3.64(3.70)$ \\
$r_{0}\left(\% \mathrm{~h}^{-1}\right)$ & $3.62(3.66)$ & $2.90(3.09)$ & $2.39(2.44)$ \\
$t_{1 / 2}(\mathrm{~h})$ & $8.86(8.74)$ & $9.89(9.30)$ & $11.76(11.54)$ \\
$q$ (bar) & $7.4(7.6)$ & $6.1(6.2)$ & $6.1(6.5)$ \\
\hline
\end{tabular}

$0.08 \%-0.42 \% \mathrm{H}$ content $\left(\mathrm{H}_{2} \%+1 / 2 \mathrm{HT} \%\right)$ were made at the rate of -1.7 bar per $1 \% \mathrm{H}$. The results are summarized in Table 5, illustrated in Fig. 4 for $P_{\mathrm{m}}<25 \mathrm{bar}$, and, over $20.83 \mathrm{~K}-22.10 \mathrm{~K}$, fit the equations:

$$
\begin{aligned}
& P_{\mathrm{m}}(\mathrm{n})=0.22+45.92(T-20.627) \text { bar, } \\
& P_{\mathrm{m}}(\mathrm{e})=0.22+45.27(T-20.568) \text { bar. }
\end{aligned}
$$

The constant 0.22 is the triple point pressure for $\mathrm{n}-\mathrm{T}_{2}$ determined from vapor pressure measurements [3], and it is assumed for e- $T_{2}$ as well. The linear $P_{\mathrm{m}}-\mathrm{T}$ relation corresponds with the $\mathrm{H}_{2}$ and $D_{2}$ curves. The greater values just above the triple 
Table 5. Melting pressure of $T_{2}$

\begin{tabular}{ccccccccc}
\hline \hline$T$ & $H \%^{\mathrm{a}}$ & $\begin{array}{c}P(\mathrm{n}) \\
\text { bar }\end{array}$ & $\begin{array}{c}P-P_{\mathrm{eq}} \\
\text { bar }\end{array}$ & $c(\mathrm{e})$ & $\begin{array}{c}t^{\mathrm{b}} \\
\mathrm{h}\end{array}$ & $\begin{array}{c}P(\mathrm{e})^{\mathrm{c}} \\
\text { bar }\end{array}$ & $\begin{array}{c}P-P_{\mathrm{eq}} \\
\text { bar }\end{array}$ & $\begin{array}{c}q \\
\text { bar }\end{array}$ \\
\hline 20.550 & 0.13 & & & 0.356 & 71 & $2.145^{\mathrm{d}}$ & & \\
20.650 & 0.13 & $3.295^{\mathrm{d}}$ & +2.02 & 0.358 & & $\left(6.196^{\mathrm{d}}\right)$ & +2.26 & 7.4 \\
20.700 & 0.21 & $4.722^{\mathrm{d}}$ & +1.15 & 0.359 & 52 & $7.053^{\mathrm{d}}$ & +0.86 & 6.0 \\
20.900 & 0.08 & & & 0.365 & 42 & 15.235 & -0.01 & 6.4 \\
21.000 & 0.08 & 17.419 & +0.07 & 0.368 & & $(19.864)$ & +0.09 & 6.4 \\
21.000 & 0.21 & & & 0.368 & 68 & 19.772 & 0.00 & 6.2 \\
21.050 & 0.22 & 19.632 & -0.01 & 0.370 & & $(22.140)$ & +0.10 & 6.6 \\
21.100 & 0.42 & 21.968 & +0.03 & 0.371 & 53 & 24.469 & +0.16 & 6.6 \\
21.390 & 0.15 & 35.198 & -0.06 & 0.379 & & $(37.239)$ & -0.19 & 5.5 \\
21.600 & 0.35 & 44.660 & -0.24 & 0.385 & & & & 5.6 \\
21.700 & 0.10 & & & 0.388 & 56 & 51.593 & +0.12 & 5.8 \\
21.750 & 0.25 & 51.751 & -0.04 & 0.389 & 58 & 53.377 & -0.35 & 4.5 \\
21.900 & 0.10 & 58.630 & -0.05 & 0.393 & & & & 6.1 \\
22.100 & 0.15 & 67.906 & +0.05 & 0.400 & & $(70.041)$ & +0.48 & 6.1 \\
22.100 & 0.15 & & & 0.400 & 52 & 69.574 & 0.00 & 4.8 \\
\hline
\end{tabular}

arrections to $P$ were made at the rate of -1.7 bar for $1 \% \mathrm{H}$.

b $t$ was the time in the condensed state when $P(\mathrm{e})$ was measured.

- Values in parentheses are from Eq. (2) fitting.

d See text for the uncertainty involved.

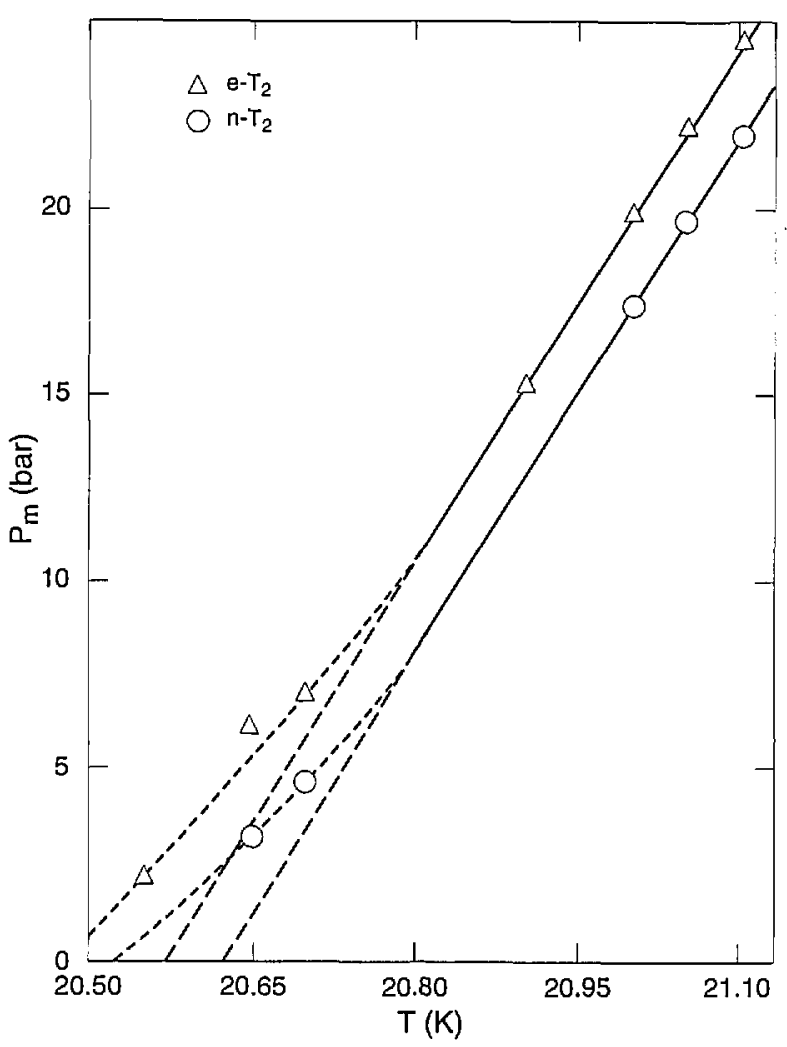

Fig. 4. Tritium melting pressure vs temperature.

point, as shown in Fig. 4, cannot be resolved at present. If Eqs. (3) and (4) held down to the triple point, the $T_{\mathrm{tp}}$ values would be $20.627 \mathrm{~K}$ for $\mathrm{n}-\mathrm{T}_{2}$ and $20.568 \mathrm{~K}$ for $\mathrm{e}-\mathrm{T}_{2}$. The $20.627 \mathrm{~K}$ value is close to $T_{\mathrm{tp}}\left(\mathrm{n}-\mathrm{T}_{2}\right)=20.62 \mathrm{~K}$, the junction of the liquid and solid vapor pressure equations [3]. Unfortunately, those equations ignored the highest point measured in the solid region, 2.116 bar at $20.547 \mathrm{~K}$. If the liquid and solid curves went through that point, $T_{\mathrm{tp}}\left(\mathrm{n}-\mathrm{T}_{2}\right)$ would be $20.547 \mathrm{~K}$, falling between the possible values from the melting curve, $20.53 \mathrm{~K}$ and $20.62 \mathrm{~K}$. The $T_{\mathrm{tp}}\left(\mathrm{e}-\mathrm{T}_{2}\right)$ seems to be in the 20.48 $\mathrm{K}-20.57 \mathrm{~K}$ range. In Table $5, P-P_{\text {eq }}$ is the difference between experimental and equation values of $P_{\mathrm{m}}$.

The sole previous $P_{\mathrm{m}}$ measurement in the present range was 56.68 bar at $21.826 \mathrm{~K}$ for $\mathrm{n}-\mathrm{T}_{2}$ by Mills and Grilly [5], which is 1.48 bar higher than the present result. Of this deviation, 0.76 bar could be from the $0.9 \%$ HT impurity in the earlier measurement. Their equation gives values that are lower than the present by 2.5 bar. An equation devised by Goodwin [22] gives values lower than the present by 0.64 bar.

\subsection{Volume Change with Time}

The increase with time seen in liquid volume $V_{1}$ at constant $T$ and $P\left(-P_{\mathrm{m}}\right)$ was also attributed to o-p conversion and ${ }^{3} \mathrm{He}$ growth. The data fit Eq.(2) where $c=0.75-\Delta V_{1} / s V_{1}, \Delta V_{1}=V_{1}(c)-V_{1}(c=0.75)$, and $s=\Delta V_{1}(0.75-c) V_{1}$ with $k_{1}=7.53 \times 10^{-2} \mathrm{~h}^{-1}$ and $s=5.7 \times 10^{-3}$ for the raw values of $\Delta V_{1} / V_{1}$ at $21.00 \mathrm{~K}$ $(c(e)=0.368)$ and 14.86 bar. In Fig. 5, the raw data deviate from the dashed equation curve, indicating 
Journal of Research of the National Institute of Standards and Technology

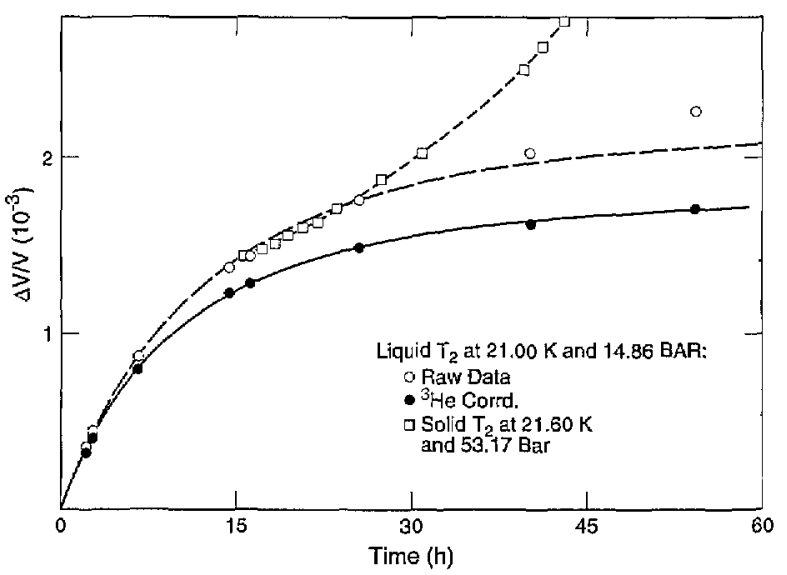

Fig. 5. Relative volume change of $T_{2}$ vs time.

that o-p conversion almost stops after $30 \mathrm{~h}$ and thereafter $V_{1}$ increases mostly from ${ }^{3} \mathrm{He}$ growth. An empirical correction to $\Delta V_{l} / V_{\mathrm{l}},-1.0 \times 10^{-5} \mathrm{~h}^{-1}$, to yield coincidence between the corrected data and the solid equation curve results in $k_{1}=8.98 \times 10^{-2} \mathrm{~h}^{-1}$ and $s=4.6 \times 10^{-3}$. The $k_{1}$ values are similar to the results from $P_{\mathrm{m}}$ (Table 4), but the $s$ values are smaller than the values for $\mathrm{H}_{2}$ : $6.5 \times 10^{-3}$ by Scott and Brickwedde [23] at vapor pressure; $6.7 \times 10^{-3}$ by Wallace and Meyer [24] at $P_{\mathrm{m}}$. Measurements of $\Delta V / V$ vs $t$ on solid $\mathrm{T}_{2}$ at $21.600 \mathrm{~K}$ and 53.17 bar were begun after the sample had been liquid for $6 \mathrm{~h}$ and solid for $9.5 \mathrm{~h}$. They were added to the $21.000 \mathrm{~K}$ liquid value at $t=15.5$ h. The results, shown in Fig. 5, follow the liquid curve for $9 \mathrm{~h}$ before rising sharply, probably because of breakup of the solid.

\subsection{Liquid Thermal Expansion and Compressibility}

The thermal expansion coefficient, $\alpha=V^{-1}$ $(\partial V / \partial T)_{P}$, and the compressibility coefficient, $\beta=-V^{-1}(\partial V / \partial P)_{T}$, of the liquid were measured directly. All $\alpha$ and $2 / 3$ of the $\beta$ measurements were made on essentially e- $T_{2}$. The measurements at $c=0.6-0.7$ fit in with the others. They would require a $+1.5 \%$ correction, at most, for the volume change from o-p conversion during the 5 min measurement, and this is within the scatter of data. The differences in $\alpha$ and $\beta$ for $n-\mathrm{H}_{2}$ and $\mathrm{e}-\mathrm{H}_{2}$ were found to be within $2 \%$. Therefore, it is assumed that the $T_{2}$ data are independent of $c$. The $\alpha$ results are given in Fig. 6 as functions of $T$ at various pressures. The dashed curve is through $T_{\mathrm{m}}$ of $\mathrm{e}-\mathrm{T}_{2}$. The $\beta$ results are shown in Fig. 7 as functions of $P$ at various temperatures, and the dashed curve is through $P_{m}$ of e- $T_{2}$.

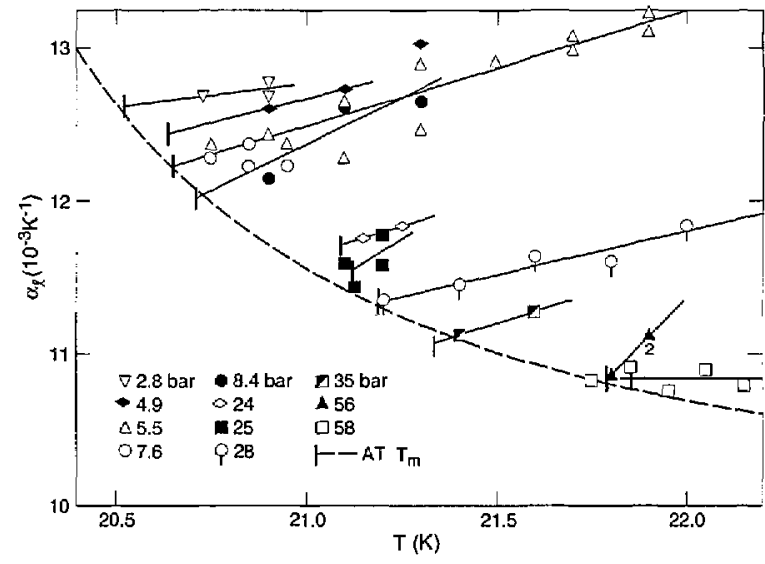

Fig. 6. Thermal expansion of liquid e-T $\mathrm{T}_{2}$ vs temperature at various pressures.

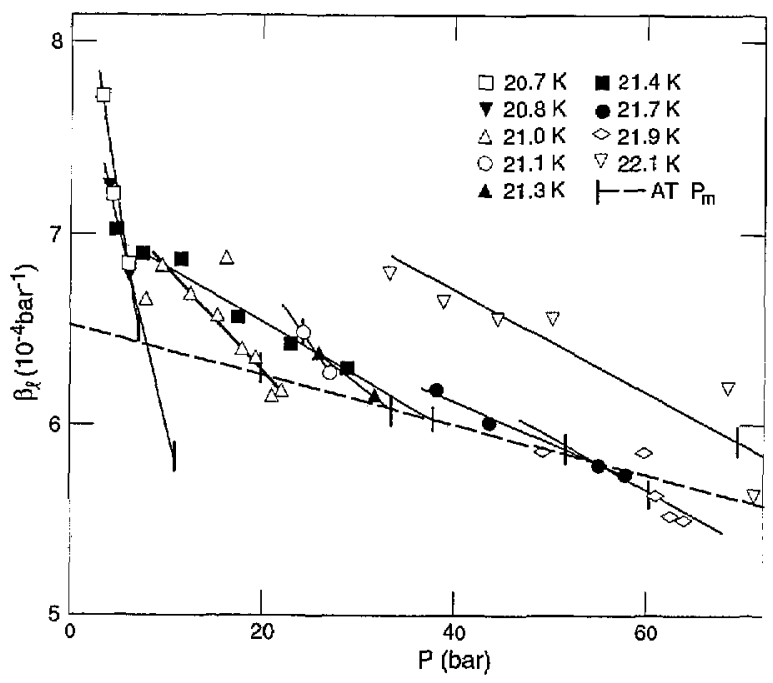

Fig. 7. Compressibility of liquid e-T $T_{2}$ vs pressure at various temperatures.

There are no other data on $\alpha$ or $\beta$ for $\mathrm{T}_{2}$. Comparison of $\alpha$ for $\mathrm{H}_{2}, \mathrm{D}_{2}[8]$ and $\mathrm{T}_{2}$ is shown in Fig. 8. The three isotopes show similar slopes $(\partial \alpha / \partial T)_{p}$ and their $\alpha$ values come together with pressure, becoming equal at 57 bar. Figure 9 shows $\beta$ for the isotopes tending to merge at high pressures.

\subsection{Molar Volumes}

The molar volume of liquid $\mathrm{T}_{2}$ along the melting curve $V_{\operatorname{lm}}$ was calculated from the measurement at the triple point [4], $22.051 \mathrm{~cm}^{3} \mathrm{~mol}^{-1}$ for $\mathrm{n}-\mathrm{T}_{2}$, and the measured $\alpha$ and $\beta$ values. This $V_{l m}$ multiplied by the measured $\Delta V_{\mathrm{m}} / V_{\mathrm{lm}}$ yielded $\Delta V_{\mathrm{m}}$, the volume change on melting. Finally, the solid molar volume 


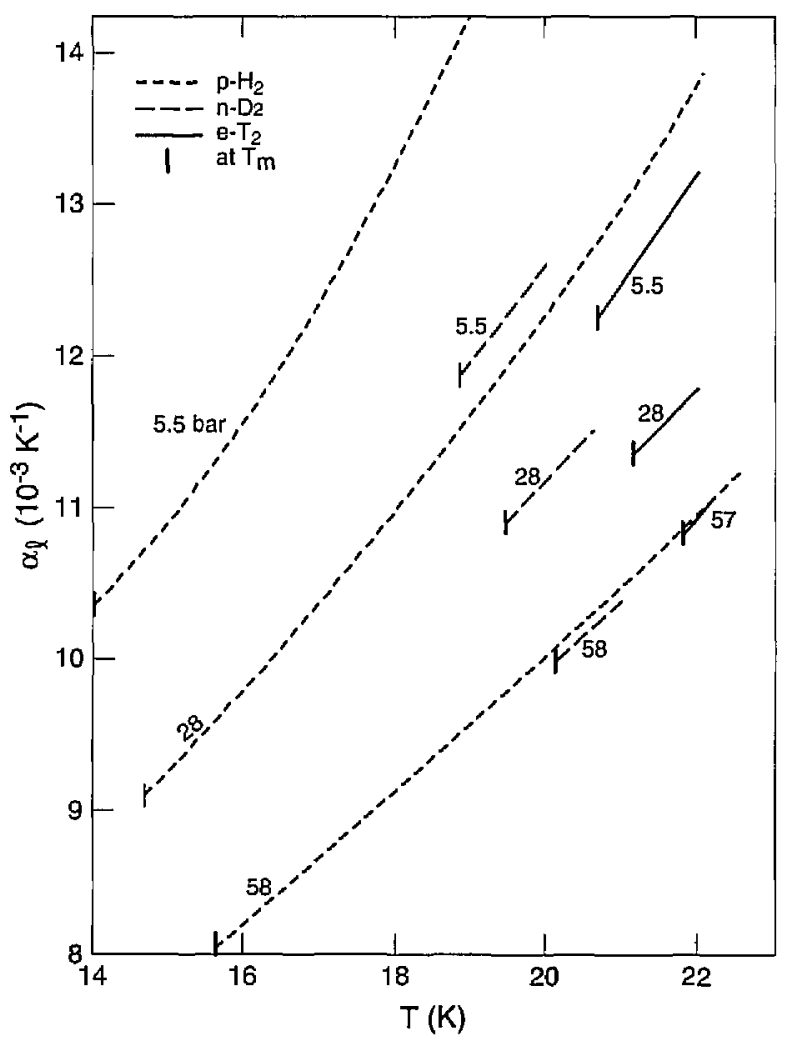

Fig. 8. Liquid thermal expansion of the hydrogens vs temperature at several pressures.

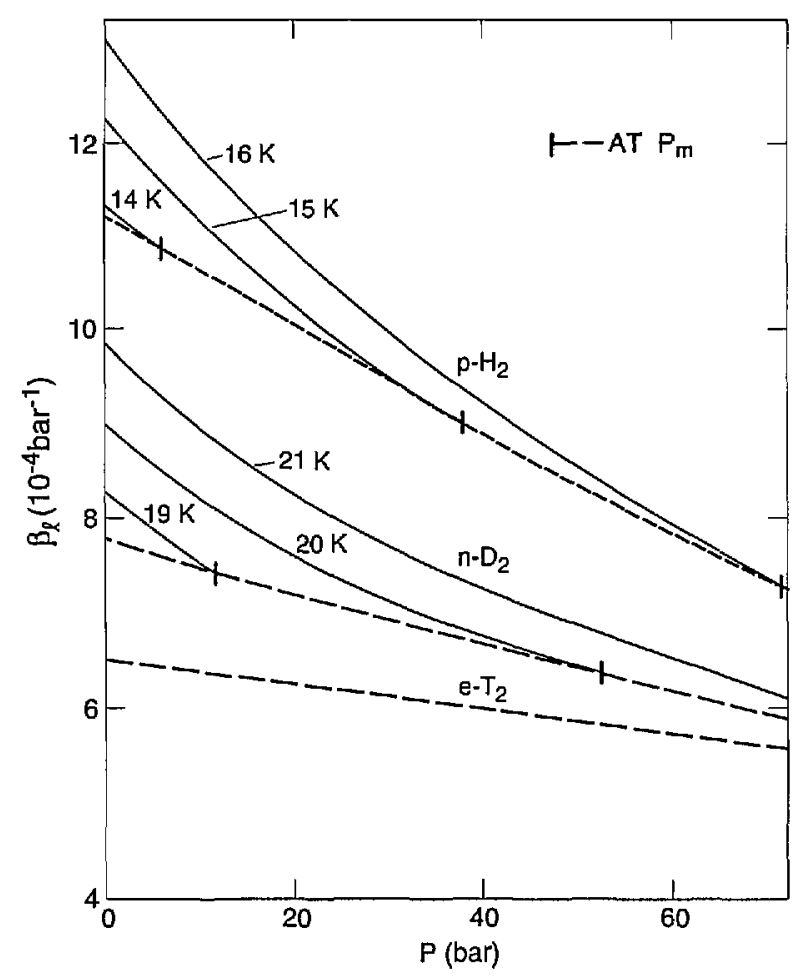

Fig. 9. Liquid compressibility of the hydrogens vs pressure at several temperatures.
$V_{\mathrm{sm}}$ was determined from $V_{\mathrm{lm}}-\Delta V_{\mathrm{m}}$. Figures 10 and 11 give the results on $\Delta V_{\mathrm{m}} / V_{\mathrm{Im}}$ and $\Delta V_{\mathrm{m}}$, respectively, for $\mathrm{T}_{2}, \mathrm{H}_{2}$, and $\mathrm{D}_{2}$ [8]. Essentially, the $\Delta V_{\mathrm{m}} /$ $V_{\mathrm{lm}}$ curves show a parallel displacement for the isotopes while the $\Delta V_{\mathrm{m}}$ curves are fairly close together. The results are given in Table 6 . All the smoothed $P V T$ values along the melting curve are summarized in Table 7 which should be self-consistent. Here, the $V_{\mathrm{lm}}$ and $V_{\mathrm{sm}}$ values are for $\mathrm{n}-\mathrm{T}_{2}$, but the values for $\mathrm{e}-\mathrm{T}_{2}$ are only slightly larger. Values of $V_{\operatorname{lm}}\left(\mathrm{e}-\mathrm{T}_{2}\right)-V_{\operatorname{lm}}\left(\mathrm{n}-\mathrm{T}_{2}\right)$ were calculated from the o-p expansion and the $P_{\mathrm{m}}\left(\mathrm{n}-\mathrm{T}_{2}\right) \rightarrow P_{\mathrm{m}}\left(\mathrm{e}-\mathrm{T}_{2}\right)$ contraction, using the $s$ values in Table 4 and the $\beta$ values in Table 7 . The two effects largely cancel

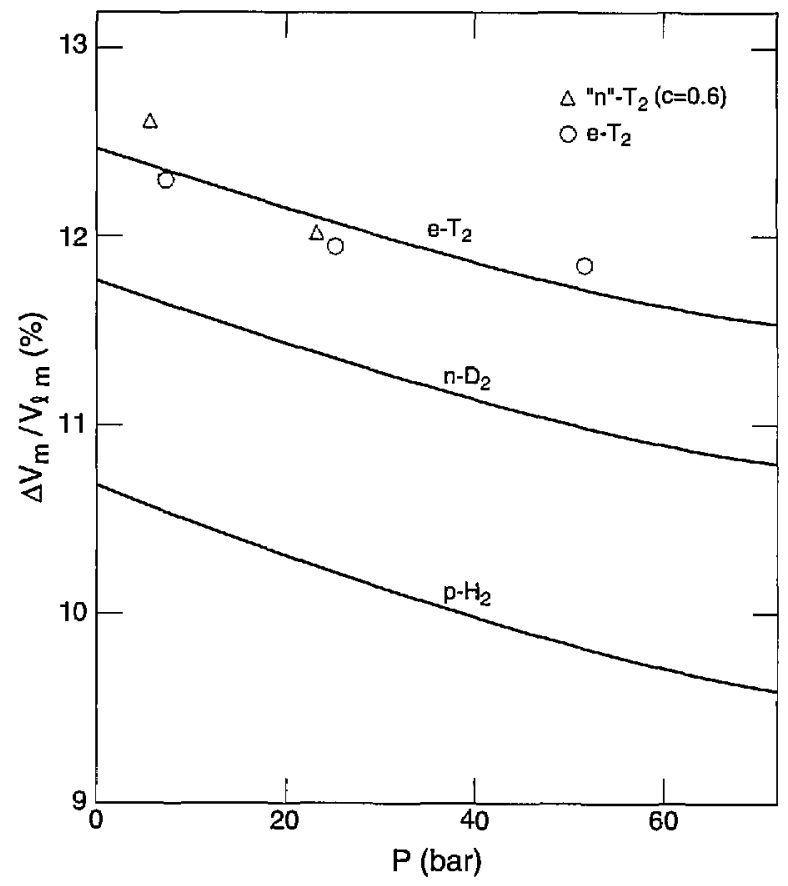

Fig. 10. Relative volume change on melting of the hydrogens.

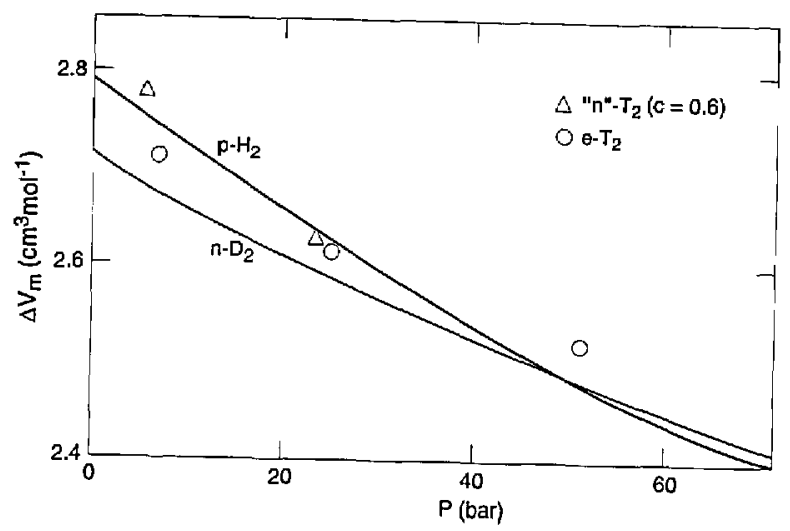

Fig. 11. Volume change on melting of the hydrogens. 
Table 6. Volume change on melting of $\mathrm{T}_{2}$

\begin{tabular}{|c|c|c|c|c|c|}
\hline $\begin{array}{l}T \\
\mathrm{~K}\end{array}$ & $\begin{array}{l}P_{\mathrm{Im}^{\mathrm{a}}} \\
\mathrm{bar}\end{array}$ & $\begin{array}{c}\Delta V_{\mathrm{m}} / V_{\mathrm{Im}}{ }^{\mathrm{a}} \\
\mathrm{F}_{0}\end{array}$ & $\begin{array}{c}V_{\operatorname{lm}} \\
\mathrm{cm}^{3} \mathrm{~mol}^{-1}\end{array}$ & $\underset{\mathrm{cm}^{3} \mathrm{~mol}^{-1}}{\Delta V_{\mathrm{m}}}$ & $\begin{array}{c}V_{\text {sm }} \\
\mathrm{cm}^{3} \mathrm{~mol}^{-1}\end{array}$ \\
\hline \multicolumn{6}{|c|}{$n-T_{2}$} \\
\hline 20.700 & 4.72 & 12.62 & 22.024 & 2.779 & 19.245 \\
\hline 21.100 & 22.23 & 12.02 & 21.881 & 2.630 & 19.251 \\
\hline \multicolumn{6}{|c|}{$e-T_{2}$} \\
\hline 20.700 & 7.05 & 12.30 & 22.026 & 2.709 & 19.317 \\
\hline 21.100 & 24.47 & 11.95 & 21.883 & 2.615 & 19.268 \\
\hline 21.700 & 51.59 & 11.86 & 21.659 & 2.569 & 19.090 \\
\hline
\end{tabular}

${ }^{a}$ Dircct measurement.

Table 7. Properties of $T_{2}$ along the melting curve

\begin{tabular}{|c|c|c|c|c|c|c|c|c|c|c|}
\hline $\begin{array}{l}T \\
\mathbf{K}\end{array}$ & $\begin{array}{c}P\left(\mathrm{n}-\mathrm{T}_{2}\right) \\
\text { bar }\end{array}$ & $\begin{array}{c}P\left(\mathrm{e}-\mathrm{T}_{2}\right) \\
\text { bar }\end{array}$ & $c(\mathrm{e})$ & $\begin{array}{c}\alpha_{7} \\
10^{-3} \\
\mathrm{~K}^{-1}\end{array}$ & $\begin{array}{c}\beta_{1} \\
10^{-4} \\
\text { bar }^{-1}\end{array}$ & $\begin{array}{c}V_{1}\left(\mathrm{n}-\mathrm{T}_{2}\right) \\
\mathrm{cm}^{3} \mathrm{~mol}^{-1}\end{array}$ & $\begin{array}{c}V_{l}\left(\mathrm{e}-\mathrm{T}_{2}\right) \\
\mathrm{cm}^{3} \mathrm{~mol}^{-1}\end{array}$ & $\begin{array}{c}\Delta V_{\mathrm{m}} / V_{1} \\
\%\end{array}$ & $\underset{\mathrm{cm}^{3} \mathrm{~mol}^{-1}}{\Delta V_{\mathrm{m}}}$ & $\begin{array}{l}V_{\mathrm{s}}\left(\mathrm{n}-\mathrm{T}_{2}\right)^{\mathrm{b}} \\
\mathrm{cm}^{3} \mathrm{~mol}^{-1}\end{array}$ \\
\hline $20.535^{\mathrm{a}}$ & 0.22 & 1.80 & 0.357 & 12.4 & 6.85 & 22.051 & 22.060 & 12.40 & 2.734 & 19.317 \\
\hline 20.700 & 4.72 & 7.05 & 0.359 & 12.2 & 6.79 & 22.024 & 22.026 & 12.35 & 2.720 & 19.304 \\
\hline 20.800 & 8.30 & 10.80 & 0.362 & 12.0 & 6.72 & 21.995 & 21.997 & 12.29 & 2.703 & 19.292 \\
\hline 20.900 & 12.76 & 15.24 & 0.365 & 11.9 & 6.65 & 21.959 & 21.961 & 12.22 & 2.683 & 19.276 \\
\hline 21.000 & 17.35 & 19.77 & 0.368 & 11.7 & 6.59 & 21.920 & 21.922 & 12.15 & 2.663 & 19.257 \\
\hline 21.100 & 21.94 & 24.30 & 0.371 & 11.6 & 6.51 & 21.881 & 21.883 & 12.08 & 2.643 & 19.238 \\
\hline 21.200 & 26.53 & 28.87 & 0.374 & 11.4 & 6.45 & 21.842 & 21.844 & 12.01 & 2.623 & 19.219 \\
\hline 21.300 & 31.12 & 33.36 & 0.377 & 11.2 & 6.39 & 21.804 & 21.806 & 11.95 & 2.606 & 19.198 \\
\hline 21.400 & 35.72 & 37.88 & 0.379 & 11.1 & 6.32 & 21.766 & 21.768 & 11.89 & 2.588 & 19.178 \\
\hline 21.500 & 40.31 & 42.41 & 0.382 & 11.0 & 6.24 & 21.728 & 21.730 & 11.83 & 2.570 & 19.158 \\
\hline 21.600 & 44.90 & 46.94 & 0.385 & 10.9 & 6.16 & 21.691 & 21.694 & 11.77 & 2.553 & 19.138 \\
\hline 21.700 & 49.49 & 51.47 & 0.388 & 10.9 & 6.10 & 21.655 & 21.659 & 11.72 & 2.538 & 19.117 \\
\hline 21.800 & 54.08 & 56.00 & 0.390 & 10.8 & 6.04 & 21.618 & 21.624 & 11.67 & 2.523 & 19.095 \\
\hline 21.900 & 58.68 & 60.52 & 0.393 & 10.8 & 5.97 & 21.582 & 21.589 & 11.62 & 2.508 & 19.074 \\
\hline 22.000 & 63.27 & 65.05 & 0.396 & 10.7 & 5.90 & 21.547 & 21.555 & 11.58 & 2.495 & 19.052 \\
\hline 22.100 & 67.86 & 69.57 & 0.400 & 10.7 & 5.82 & 21.512 & 21.521 & 11.54 & 2.482 & 19.030 \\
\hline
\end{tabular}

"See text on the triple point.

${ }^{\mathrm{b}} V_{\mathrm{s}}\left(\mathrm{e}-\mathrm{T}_{2}\right)-V_{\mathrm{s}}\left(\mathrm{n}-\mathrm{T}_{2}\right)=V_{1}\left(\mathrm{e}-\mathrm{T}_{2}\right)-V_{1}\left(\mathrm{n}-\mathrm{T}_{2}\right)$.

each other, leaving a net difference of only 0.002 $\mathrm{cm}^{3} \mathrm{~mol}^{-1}$ for the most part, with high values of 0.009 at $20.535 \mathrm{~K}$ and $22.1 \mathrm{~K}$. The result is carried over to $V_{\mathrm{sm}}$ since $\Delta V_{\mathrm{m}} / V_{\mathrm{lm}}$ is assumed to be independent of $c$.

The possibility of comparison with other work is small. Hammel [25] predicted $\Delta V_{\mathrm{m}}=2.66 \mathrm{~cm}^{3} \mathrm{~mol}^{-1}$ at the triple point, whereas here we get 2.734 . Driessen et al. [26] calculated values of $V_{\mathrm{sm}}$ that are $0.05 \mathrm{~cm}^{3} \mathrm{~mol}^{-1}-0.07 \mathrm{~cm}^{3} \mathrm{~mol}^{-1}$ lower than ours over $20.535 \mathrm{~K}-22.1 \mathrm{~K}$ range.

\subsection{Solid Thermal Expansion and Compressibility}

The measurements of $\alpha$ and $\beta$ for the solid phase gave erratic and probably low values in general.
This behavior can be expected from poor pliability of the solid in the measuring cell, which tends to be worse away from the melting curve [8]. The behavior occurred in all the isotopes, but $T_{2}$ has other properties that could influence the measurements: ${ }^{3} \mathrm{He}$ production, internal heating, and solid fracturing. Although the measurements were made on $e-T_{2}$ the results can probably be used for any o-p composition.

For each of $\mathrm{H}_{2}, \mathrm{D}_{2}$, and $\mathrm{T}_{2}, \alpha$ was measured at several pressures as a function of $T$, and each time it increased with $T$. However, $\alpha$ at constant $T$ generally decreases with $P$. Thus the extrapolations of $\alpha$ to $T_{\mathrm{m}}$ can lead to roughly constant values, which occurs for $\mathrm{H}_{2}$ and $\mathrm{D}_{2}$ [8]. However $\alpha$ increases with $T_{\mathrm{m}}$ for $\mathrm{T}_{2}$. Figure 12 illustrates these behaviors, 


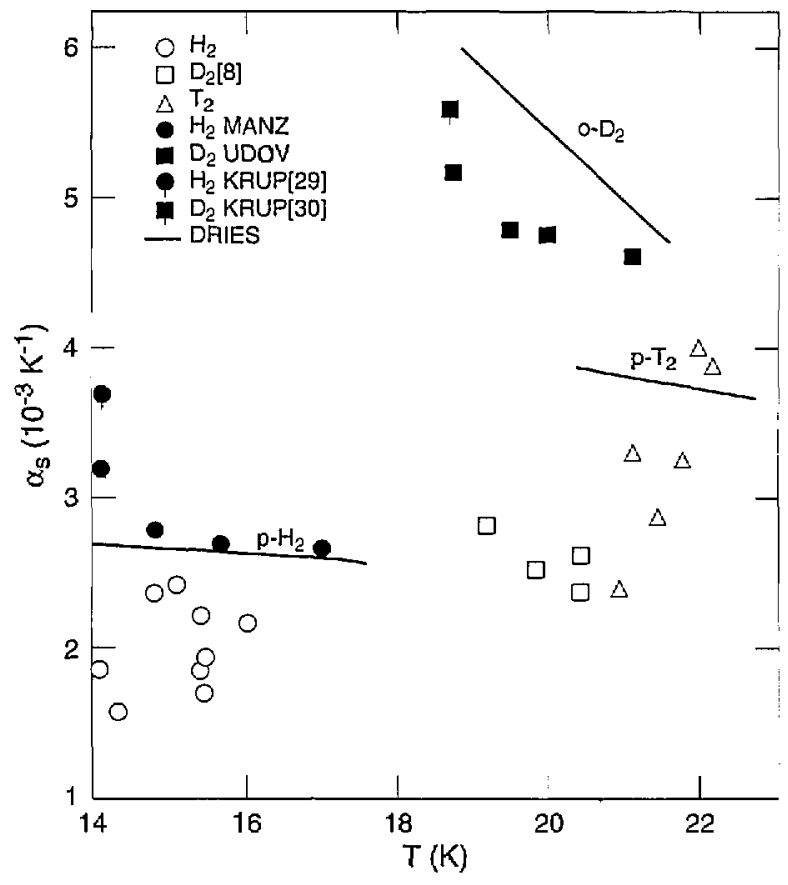

Fig. 12. Solid thermal expansion of the hydrogens along the melting curve. MANZ is Manzhelii et al. [27]; UDOV is Udovidchenko et al. [28]; KRUP [29] is Krupskij et al. [29]; KRUP [30] is Krupskii et al. [30]; DRIES is Driessen et al. [26].

along with the overall increase in $\alpha$ from $\mathrm{H}_{2}$ to $\mathrm{D}_{2}$ to $\mathrm{T}_{2}$. The results of Driessen et al. [26] are also shown there. They measured the isochores of $\mathrm{p}-\mathrm{H}_{2}$ and $o-D_{2}$ up to $2 \mathrm{kbar}$, between the melting curve and $4.2 \mathrm{~K}$, by use of a cell whose wall deflections were measured with strain gauges. Molar volumes were determined by correlation with data at the melting line and $4.2 \mathrm{~K}$. Isochores were fit by integration of specific heat. The resulting equation of state was used to calculate $V, \alpha$, and $\beta$ up to 25 kbar. The derivation of an EOS for $\mathrm{p}-\mathrm{T}_{2}$ was "guided by experimental results for $\mathrm{H}_{2}$ and $\mathrm{D}_{2}$." Their $\alpha$ results appear to be in rough agreement with ours for $\mathrm{H}_{2}$ and $\mathrm{T}_{2}$ but for $\mathrm{D}_{2}$ they are about twice as great. Densities were derived from dielectric constant measurements on $\mathrm{p}-\mathrm{H}_{2}$ by Manzhelii et al. [27] and on $\mathrm{n}-\mathrm{D}_{2}$ by Udovidchenko et al. [28]. Their $\alpha$ results (good to $\pm 10 \%$ ), shown in Fig. 12, match the Driessen et al. results for $\mathrm{H}_{2}$ very well and for $\mathrm{D}_{2}$ within $15 \%$. From $\mathrm{x}$-ray studies of lattice parameters, Krupskii et al. [29,30] derived $\alpha$ for $\mathrm{p}-\mathrm{H}_{2}$ that is $37 \%$ higher than the Driessen et al. result and $\alpha$ for $\mathrm{o}-\mathrm{D}_{2}$ that is $8 \%$ lower.

The measurements of $\beta$ as a function of $P$ at several temperatures show a decrease with $P$. Generally, $\beta$ increases with $T$, therefore, the extrapolated values of $\beta$ to $P_{\mathrm{m}}$ can be almost constant, as illustrated in Fig. 13. There is also a big decrease in $\beta$ from $\mathrm{H}_{2}$ to $\mathrm{D}_{2}$ to $\mathrm{T}_{2}$. The values for $\mathrm{H}_{2}, \mathrm{D}_{2}$ [8], and $T_{2}$ are about $0.90,0.55$, and 0.77 , respectively, of the Driessen et al. [26] results. The measurements of Manzhelii et al. [27] and of Udovidchenko and Manzhelii [31] on $\beta$ of $\mathrm{p}-\mathrm{H}_{2}$ are $5 \%-10 \%$ greater than those of Driessen et al. [26] while the values of Udovidchenko et al. [28] for $n-D_{2}$ are slightly lower. Other measurements on $\mathrm{H}_{2}$ and $\mathrm{D}_{2}$ were made at $4.2 \mathrm{~K}$ using various direct and indirect techniques. In general, the values are low. In some cases, values of $P$ were not low enough to allow satisfactory extrapolations.

In spite of these discrepancies in $\alpha$ and $\beta$ results, there is hope for more accurate values for $T_{2}$. Overall, the Driessen et al. [26] results on $\mathrm{H}_{2}$ and $\mathrm{D}_{2}$ fit in fairly well with others. It follows that their $\mathrm{T}_{2}$ results should be credible. For example, the change in $V_{s}$ along the melting curve between 20.5

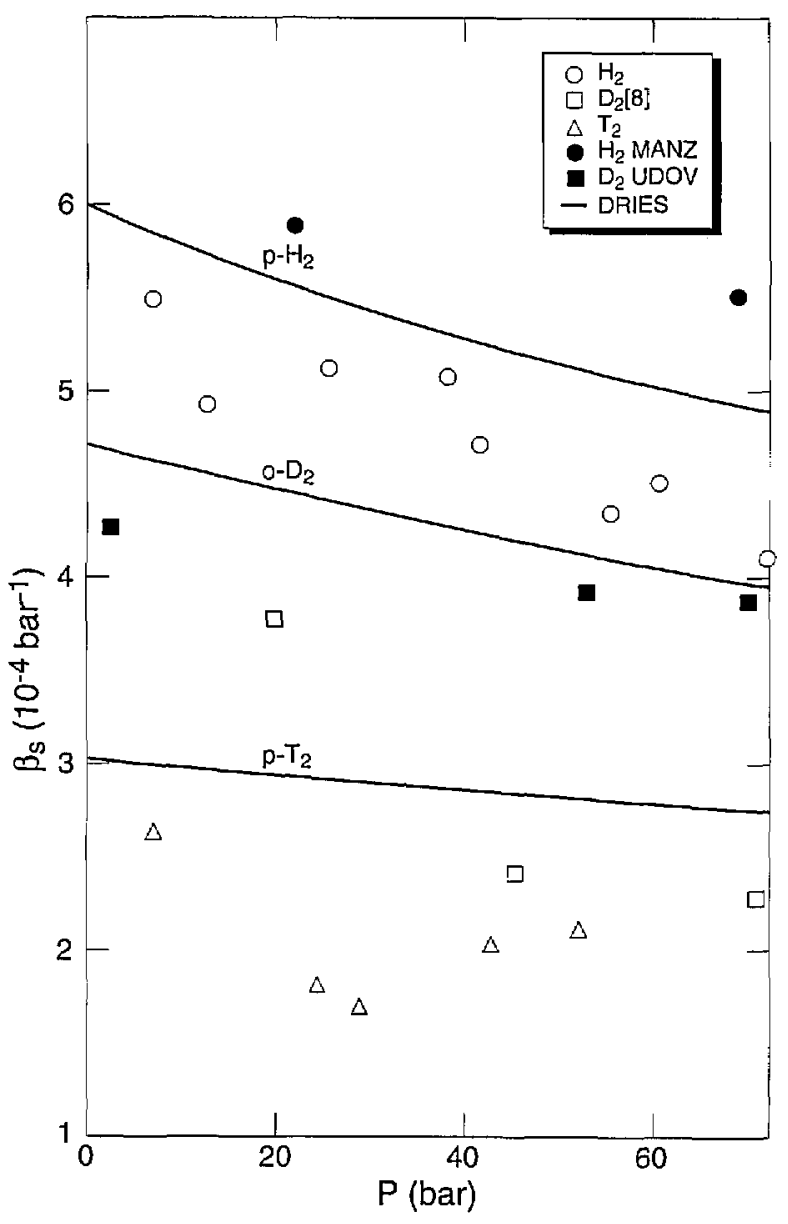

Fig. 13. Solid compressibility of the hydrogens along the melting curve. MANZ is Manzhelii et al. [27,31]; UDOV is Udovidchenko et al. [28]; DRIES is Driessen et al. [26]. 
$\mathrm{K}$ and $22.1 \mathrm{~K}$ is calculated from their $\alpha$ and $\beta$ values to be $0.252 \mathrm{~cm}^{3} \mathrm{~mol}^{-1}$, in reasonable agreement with $\Delta V_{\mathrm{s}}=0.287$ in Table 7 .

In solid $\mathrm{H}_{2}$ and $\mathrm{D}_{2}$, some anomalies in $\alpha$ and $\beta$ were observed [8] but hardly deserve recognition as phase change effects. There is no point adding to the confusion in this subject $[27,28,29,30,32,33]$. In $T_{2}$, no anomaly was recognized, but observation was very limited.

\subsection{Thermal Results}

The enthalpy change on melting (heat of fusion) calculated from the Clapeyron equation $\Delta H_{\mathrm{m}}=T \Delta V_{\mathrm{m}} \mathrm{d} P_{\mathrm{m}} / \mathrm{d} T$, using the present $P V T$ measurements on $\mathrm{n}-\mathrm{T}_{2}$, is almost constant at $255 \mathrm{Jmol}^{-1}$ in the range $20.9 \mathrm{~K}-22.1 \mathrm{~K}$ or 13 bar- 70 bar. However, below $20.9 \mathrm{~K}$ the rapid decrease in $\mathrm{d} P_{\mathrm{m}} / \mathrm{d} T$ lowers it to $144 \mathrm{Jmol}^{-1}$ at $T_{\mathrm{tp}}$. On the other hand, $\Delta H_{\mathrm{m}}$ for $\mathrm{H}_{2}$ and $\mathrm{D}_{2}$ varies linearly with $P_{\mathrm{m}}$ over 0 bar-70 bar from $117 \mathrm{Jmol}^{-1}$ to $130 \mathrm{Jmol}^{-1}$ for $\mathrm{p}-\mathrm{H}_{2}$, according to Dwyer et al. [34], and from 197 to 210 for $n-D_{2}$ [8]. If we wish to focus more on the similarities of the isotopes, perhaps it would be better to compare the behavior of the entropy change $\Delta S_{\mathrm{m}}=\Delta H_{\mathrm{m}} / T$. This decreases over 13 bar-70 bar by $2 \%$ for $\mathrm{H}_{2}$ and $\mathrm{D}_{2}$ and by $4 \%$ for $\mathrm{T}_{2}$.

\section{Summary}

The $P V T$ relations in liquid and solid $\mathrm{T}_{2}$ were measured near the melting curve over $20.5 \mathrm{~K}-22.1$ $\mathrm{K}$ and 0 bar- 70 bar. They were compared with measurements on $\mathrm{H}_{2}$ and $\mathrm{D}_{2}$ and with calculations on $\mathrm{T}_{2}$. Comparison of the three isotopes leads to few surprises. The melting pressure variations with temperature and ortho-para composition are consistent. An exception is the strange behavior of $P_{\mathrm{m}}$ for $T_{2}$ in the $0.3 \mathrm{~K}$ interval just above the triple point. The o-p conversion in condensed $T_{2}$ is faster than in $\mathrm{H}_{2}$ but slow enough to allow observation of its effect on the $P V T$ relations. The liquid and solid molar volumes of the three isotopes are consistent in magnitude and in their variations with o-p composition, pressure, and temperature. Still unresolved is the status of ${ }^{3} \mathrm{He}$ produced in condensed $\mathrm{T}_{2}$.

\section{Acknowledgment}

I thank J. K. Hoffer and R. H. Sherman for sharing their observations on ${ }^{3} \mathrm{He}$ in condensed $\mathrm{T}_{2}$.

\section{References}

[1] H. C. Urey, F. G. Brickwedde, and G. M. Murphy, Phys. Rev. 39, 164 (1932).

[2] M. L. E. Oliphant, P. Harteck, and Lord Rutherford, Proc. Roy. Soe. 144 A, 692 (1934).

[3] E. R. Grilly, J. Am. Chem. Soe. 73, 843 (1951).

[4] E. R. Grilly, J. Am. Chem. Soe. 73, 5307 (1951).

[5] R. L. Mills and E. R. Grilly, Phys. Rev. 101, 1246 (1956).

[6] E. R. Grilly, J. Low Temp. Phys. 4, 615 (1971).

[7] E. R. Grilly, J. Low Temp. Phys. 11, 33 (1973).

[8] L. A. Schwalbe and E. R. Grilly, J. Res. Natl. Bur. Stand. (U.S.) 89, 227 (1984).

[9] L. A. Sehwalbe and E. R. Grilly, J. Res. Natl. Bur. Stand. (U.S.) 89, 317 (1984).

[10] D. A. Depatie and R. L. Mills, Rev. Sei. Instr. 39, 105 (1968).

[11] W. M. Jones, J. Chem. Phys. 16, 1077 (1948).

[12] J. R. Gaines, R. T. Tsugawa, and P. C. Souers, Phys. Rev. Lett. 42, 1717 (1979).

[13] R. Frauenfelder, F. Heinrich, and J. B. Olin, Helv. Phys. Aeta 38, 279 (1965).

[14] E. R. Grilly, Proceedings of the Third International Conferenee on Low Temperature Physies and Chemistry, Houston (1953) p. 66.

[15] J. D. Sater, J. R. Gaines, E. M. Fearon, P. C. Souers, F. E. MeMurphy, and E. R. Mapoles, Phys. Rev. B 37, 1482 (1988).

[16] E. W. Albers, P. Harteck, and R. R. Reeves, J. Amer. Chem. Soc. 86, 204 (1964).

[17] H. W. Woolley, R. B. Scott, and F. G. Brickwedde, J. Res. Natl. Bur. Stand. (U.S.) 41, 454 (1948).

[18] N. G. Bereznyak and A. A. Sheinina, Fiz. Nizk. Temp. 7, 685 (1981). [Sov. J. Low Temp. Phys. 7, 335 (1981)].

[19] R. D. Taylor, Proeeedings of the 17th International Conference on Low Temperature Physics, Karlsruhe, 1984, part II, Paper EL 10.

[20] J. K. Hoffer and L. R. Foreman, Phys. Rev. Lett. 60, 1310 (1988).

[21] B. A. Youngblood, J. Chem. Phys. 48, 4181 (1968).

[22] R. D. Goodwin, Cryogenies 2 (6) 353 (1962).

[23] R. B. Seott and F. G. Briekwedde, J. Res. Natl. Bur. Stand. (U.S.) 19, 237 (1937); J. Chem. Phys. 5, 736 (1937).

[24] B. A. Wallace and H. Mcyer, Proeecdings of the 13th International Conference on Low Tcmperaturc Physies, Boulder, CO, Vol. 2 (1972) p. 194.

[25] E. F. Hammel, J. Chem. Phys. 18, 228 (1950).

[26] A. Driessen, Thesis, Univ. of Amsterdam (1982); A. Driessen and I. F. Silvera, J. Low Temp. Phys. 54, 565 (1984).

[27] V. G. Manzhelii, B. G. Udovidchenko, and V. B. Esel'son, Fiz. Nizk Temp. 1, 799 (1975). [Sov. J. Low Temp. Phys. 1, 384 (1975)]. Also: V. G. Manzhelii, B. G. Udovidchenko, and V. B. Esel'son, Zh. Eksp. Teor. Pisma 18, 30 (1973). [Sov. Phys.-JETP Letters 18, 16 (1973)]. B. G. Udovidchenko, V. G. Manzhelii, and V. B. Esel'son, Phys. Status Solidi (a) 19, K189 (1973).

[28] B. G. Udovidchenko, V. B. Esel'son, and V. G. Manzhelii, Fiz. Nizk Temp. 10, 13 (1984). [Sov. J. Low Temp. Phys. 10, 5 (1984)].

[29] I. N. Krupskii, A. I. Prokhvatilov, and G. N. Sheherbakov, Fiz. Nizk. Temp. 9, 83 (1983). [Sov. J. Low Temp. Phys. 9, 42 (1983). 
[30] I. N. Krupskii, A. I. Prokbvatilov, and G. N. Shcherbakov, Fiz. Nizk Temp. 10, 5 (1984). [Sov. J. Low Temp. Phys. 10, 1 (1984)].

[31] B. G. Udovidchenko and V. G. Manzhelii, J. Low Temp. Phys. 3, 429 (1970).

[32] N. G. Bereznyak and A. A. Sheinina, Fiz. Nizk Temp. 6, 1255 (1980) [Sov. J. Low Temp. Phys. 6, 608 (1980)].

[33] G. N. Shcherbakov, A. I. Prokhvatilov, and I. N. Krupskii, Fiz. Nizk Temp. 11, 521 (1985). [Sov. J. Low Temp. Phys. 11, 284 (1985)].

About the author: E. R. Grilly is a physicist retired from the Condensed Matter and Thermal Physics Group of Los Alamos National Laboratory, in which this work was done. 